\title{
A meta-analysis of the effect of pasture access on the lipid content and fatty acid composition of lamb meat
}

\author{
Teodora Popova ${ }^{\mathrm{a}, *}$, Ursula Gonzales-Barron ${ }^{\mathrm{b}}$, Vasco Cadavez ${ }^{\mathrm{b}}$ \\ ${ }^{a}$ Institute of Animal Science, 2232 Kostinbrod, Bulgaria \\ b CIMO Mountain Research Centre, School of Agriculture, Polytechnic Institute of Braganza, Campus de Santa Apolónia, 5300 Bragança, Portugal
}

\section{A R T I C L E I N F O}

\section{Article history:}

Received 3 June 2015

Received in revised form 13 July 2015

Accepted 15 August 2015

Available online 21 August 2015

\section{Keywords:}

Meta-analysis

Pasture

Indoors rearing

Lamb

Monounsaturated

Polyunsaturated

Fatty acids

\begin{abstract}
A B S T R A C T
A meta-analysis on the influence of the pasture on the lipid content and fatty acid profile in lamb meat was conducted. A total of 20 studies were selected and data on total lipid content, saturated, mono- and polyunsaturated fatty acids in lamb meat were extracted for two population groups, indoors, and pastured. Due to the high between-study heterogeneity, separate random-effects models were applied to the raw mean difference (effect size parameterization) for each of the outcomes. The results of the meta-analysis pointed that access to pasture tended to decrease the fat content in lamb, while increasing the saturated fatty acids $(P<0.05)$. The amounts of monounsaturated and n-6 polyunsaturated fatty acids were decreased $(\mathrm{P}<0.05)$. On the other hand, grazing led to substantial increase in the content of $n-3$ polyunsaturated fatty acids, and decrease $(P<0.01)$ of the ratio $n-6$ $\mathrm{n}-3$ in lamb meat, thus suggesting that pasture rearing can be recommended for improvement of meat dietetic quality.
\end{abstract}

(c) 2015 Elsevier Ltd. All rights reserved.

\section{Introduction}

Meat is an important component of a healthy human diet. However, besides the considerable amount of protein, vitamins, and minerals that it provides, meat is also a major source of fat. Although improving the sensory quality, the increased amounts of fat in meat, especially rich in saturated fatty acids, might have negative effect on the human health since its over-consumption is associated with higher risk of obesity, diabetes, and cardiovascular disease. Meat from ruminant animals has relatively high content of saturated fatty acids due to the biohydrogenation process, and hence considered less healthy. Although the possibilities to alter the fatty acid composition in ruminants are much more limited than in monogastric animals, numerous investigations focus on the ways of dietary manipulation of the lipid profile through various ruminant feeding strategies or rearing systems.

The beneficial effect of pasture rearing on the lipid profile in ruminant meats, mainly through increasing the content of $n-3$ polyunsaturated fatty acids, has been reported (Gatellier, Mercier, \& Renerre, 2004; Cividini, Levart, \& Zgur, 2008; Cividini, Levart, Žgur, \& Kompan, 2014). Furthermore, some reviews addressing the effects of various rearing systems or feeding on the fatty acid profile in meat are available (Bas \& Morand-Fehr, 2000; Wood et al., 2008), based on synthesis of the

\footnotetext{
* Corresponding author.

E-mail address: tlpopova@yahoo.com (T. Popova).
}

results from individual studies. However, as only few quantitative methods are applied to those synthetic reviews, they become narratives with subjective and qualitative summaries, which draw the conclusions based on the results of null hypothesis significance testing and do not account for the variability between primary studies as in Osenberg and St. Mary (1998) or Sales (2009).

Using meta-analysis allows to quantitatively estimate the effects and their precision as calculated from the results of individual research studies, even with opposite results (Fernandez-Duque, 1997) and to describe the overall strength of the effect, and in which circumstances that it is stronger or weaker (DeCoster, 2004). Additionally, according to Carriquiry, Weber, and Crooker (2008), meta-analysis might be particularly useful when small sample sizes limit statistical power of individual studies to detect differences. The aim of the present study was to quantify the effect of pasture access on the total intramuscular lipid content, as well as the content of saturated, monounsaturated, and polyunsaturated fatty acids in lamb meat.

\section{Material and methods}

\subsection{Literature search and selection of studies}

Extensive computerized literature search through Web of Science, PubMed, Scopus databases, publishers' websites, and Google was performed to select studies assessing the effect of pasture vs. indoors 
rearing on the content of intramuscular lipids and fatty acid composition in lamb meat. Keyword combinations of "lamb", "fatty acid", "fatty acid composition", "meat", and "pasture" were used in the search. As the first requirement for inclusion in the meta-analysis, the primary studies had to be published as peer-reviewed articles or conference proceedings in English, Portuguese or French. Each observation in the meta-analysis corresponded to the mean or least-squares mean of each treatment group (i.e., pasture and indoors rearing). The variables or outcomes extracted from each of the primary studies were: intramuscular fat content (TL), saturated fatty acids (SFA), monounsaturated fatty acids (MUFA), polyunsaturated fatty acids (PUFA), n-3 and n-6 polyunsaturated fatty acids (n-3 PUFA, n-6 PUFA), and the ratio n-6/n3 in the lamb meat. The selected publications were further required to provide any measure on intra-experiment variation, expressed either as standard error (SE) or standard deviation (SD) of the mean of each treatment group, or alternatively as mean square error (MSE) or root mean square error (RMSE).

\subsection{Description of data sets}

After assessing all available information, a total of 20 studies, providing appropriate data and measures of variance for the outcomes, were deemed suitable for inclusion in the meta-analysis (Table. 1 ). The rearing conditions of the animals on concentrate diets were described mostly as indoor (Aurousseau et al., 2007; Joy, Ripoll, \& Delfa, 2008; Kaczor, Borys, \& Pustkowiak, 2010; Nürnberg et al., 2001; Nuernberg et al., 2005; Popova, 2007; Popova \& Marinova, 2013; Popova, 2014) or drylot (Cañeque et al., 2003; Panea, Carrasco, Ripoll, \& Joy, 2011; Rowe, Macedo, Visentainer, Souza, \& Matsushita, 1999; Velasco et al., 2001). Sheepfold was used by Diaz et al. (2002) and Santé-Lhoutellier, Engel, and Gatellier (2008), while feedlot was used by Rhee, Lupton, Ziprin, and Rhee (2003a,b). In the studies of Luciano et al. (2012) and Scerra et al. (2011), lambs were stall-fed, while Fernandes et al. (2010) and Guler, Aktumsek, and Karabacak (2011) referred to the 'control' and 'treatment' as 'confined' and 'concentrate' groups, respectively. The composition of concentrates fed to the lambs was reported in twelve studies. They were mostly based on barley (Aurousseau et al., 2007; Kaczor et al., 2010; Luciano et al., 2012; Scerra et al., 2011), maize (Guler et al., 2011; Popova, 2007; Popova, 2014; Popova \& Marinova, 2013) while in the experiments of Rhee et al. (2003a,b), the main ingredient of the indoors diet was sorghum. Five of the studies reported results from experiments with suckling lambs (Joy et al., 2008;
Nuernberg et al., 2005; Panea et al., 2011; Velasco et al., 2001), while Aurousseau et al. (2007) used both weaned (on pasture) and not weaned (for the indoor). The weaned lambs having access to pasture grazed either pasture alone (Aurousseau et al., 2007; Fernandes et al., 2010; Guler et al., 2011; Luciano et al., 2012; Nürnberg et al., 2001; Rowe et al., 1999; Santé-Lhoutellier et al., 2008; Scerra et al., 2011) or received concentrate as the indoors lambs (Cañeque et al., 2003; Diaz et al., 2002; Kaczor et al., 2010; Rhee et al., 2003a,b; Popova, 2007; Popova, 2014; Popova \& Marinova, 2013). Most of the studies determined the lipid content and fatty acid composition in $\mathrm{m}$. Longissimus dorsi, more specifically Longissimus thoracis (Aurousseau et al., 2007; Joy et al., 2008; Scerra et al., 2011; Velasco et al., 2001), Longissimus lumborum (Cañeque et al., 2003; Fernandes et al., 2010; Kaczor et al., 2010; Popova, 2007). Rhee et al. (2003a,b) used samples of $\mathrm{m}$. Semimembranosus.

\subsection{Data analysis}

To summarize the influence of access to pasture and indoors rearing on a given outcome variable (TL, SFA, MUFA, PUFA, n-3, n-6 PUFA or the ratio $n-6 / n-3$ in lamb meat), for each of the primary studies the effect size measure of such outcome $\left(E S_{\text {outcome }}\right)$ was calculated as:

$\mathrm{ES}_{\text {Outcome }}=\overline{\text { Outcome }}_{\text {indoors }}-\overline{\text { Outcome }}_{\text {pastured }}$.

Thus, the effect size method allows the comparison of the means of the outcomes measured for the two population groups, indoors, and pastured. The parameterization of raw difference between means (D) is the most obvious and basic estimate of the effect size (Borenstein, Hedges, Higgins, \& Rothstein, 2009). According to some researchers, it is sufficient and even superior to other ways of parameterization of the effect size (Baguley, 2009; Wilkinson and the APA Task Force on Statistical Inference, 1999). It enables an easy comparison of results with other studies using the same measurement (Fritz, Morris, \& Richler, 2012). For each of the primary studies, the asymptotic standard error of the effect size was calculated as:

$S E_{D}=\sqrt{\frac{n_{1}+n_{2}}{n_{1} n_{2}}} S_{\text {pooled }}^{2}$

Where $\mathrm{n}_{1}$ is the sample size of the pastured group, $\mathrm{n}_{2}$ the sample size of the indoors group, $\mathrm{s}^{2}$ pooled is the pooled standard deviation.

Table 1

Description of the primary studies included in the meta-analysis.

\begin{tabular}{|c|c|c|c|c|c|c|}
\hline Reference & Country & Breed & Weaned & $\begin{array}{l}\text { Live weight at } \\
\text { slaughter }\end{array}$ & $\begin{array}{l}\text { Trial period } \\
\text { (access to pasture) }\end{array}$ & Observed outcome* \\
\hline Aurousseau et al., 2007 & France & Ile de France & Yes & 34.5 & 109 & TL, SFA, MUFA, n-3, n-6, n-3/n-6 \\
\hline Cañeque et al., 2003 & Spain & Talaverana & Yes & 28.0 & 46 & SFA, MUFA, PUFA \\
\hline Diaz et al., 2002 & Spain & Talaverana & Yes & 24.0 & 58 & TL, SFA, MUFA, PUFA, n-6/n-3 \\
\hline Fernandes et al., 2010 & Brazil & Suffolk & Yes & 32.0 & 87 & MUFA, PUFA, n-3, n-6 \\
\hline Guler et al., 2011 & Turkey & Akkaraman & Yes & 40.6 & 90 & SFA, MUFA, PUFA, n-3, n-6, n-6/n-3 \\
\hline Joy et al., 2008 & Spain & Churra Tensina & No & 23.0 & 80 & TL, SFA, MUFA, PUFA, n-3, n-6, n-6/n-3 \\
\hline Kaczor et al., 2010 & Poland & Koluda, Il de France $\times$ Koluda & Yes & 35.5 & 40 & TL, SFA, MUFA, PUFA, n-3, n-6/n-3 \\
\hline Rhee et al., 2003a & USA & Merino $\times$ Rambouillet & Yes & 59.0 & 168 & SFA, MUFA, PUFA \\
\hline Rhee et al., 2003b & USA & Rambouillet & Yes & 59.0 & 108 & SFA, MUFA, PUFA \\
\hline Luciano et al., 2012 & Italy & Merinizzata Italiana & Yes & 19.83 & 92 & TL, PUFA \\
\hline Nürnberg et al., 2001 & Germany & Rough wool Pomeranian Landrace & Yes & 40.0 & 107 & TL, SFA, n-3, n-6, n-6/n-3 \\
\hline Nuernberg et al., 2005 & Germany & Black Head $\times$ Gotland & No & 40.0 & 115 & TL, SFA, PUFA, n-3, n-6, n-6/n-3 \\
\hline Panea et al., 2011 & Spain & Churra Tensina & No & 22.0 & 74 & TL, SFA, MUFA, PUFA, n-6/n-3 \\
\hline Popova, 2007 & Bulgaria & Zapadnostaroplaninska & Yes & 19.3 & 60 & $\mathrm{TL}$ \\
\hline Popova, 2014 & Bulgaria & North Eastern Bulgarian Fine wool & Yes & 31.5 & 73 & SFA, MUFA, PUFA \\
\hline Popova \& Marinova, 2013 & Bulgaria & North Eastern Bulgarian Fine wool & Yes & 31.5 & 73 & $\mathrm{TL}$ \\
\hline Rowe et al., 1999 & Brazil & $\begin{array}{l}\text { Corriedale, Bergamacia } \times \text { Corriedale, } \\
\text { Hampshire Down } \times \text { Corriedale }\end{array}$ & Yes & 30.0 & na & TL, SFA, MUFA \\
\hline Santé-Lhoutellier et al., 2008 & France & Texel $\times$ Romanov & Yes & 30.9 & 169 & TL, SFA, MUFA, PUFA, n-3, n-6 \\
\hline Scerra et al., 2011 & Italy & Italian Merino & Yes & na & 89 & TL, SFA, MUFA, PUFA, n-3, n-6, n-6/n-3 \\
\hline Velasco et al., 2001 & Spain & Talaverana & No & 14 & na & TL, SFA, MUFA, PUFA, n-6/n-3 \\
\hline
\end{tabular}

* TL: total lipids, SFA: saturated fatty acids, MUFA: monounsaturated fatty acids, PUFA-polyunsaturated fatty acids. 
According to the available data in the studies, the value of $S_{\text {pooled }}$ was estimated as:

Spooled $=\sqrt{\frac{\left(n_{1}-1\right) s_{1}^{2}+\left(n_{2}-1\right) s_{2}^{2}}{n_{1}+n_{2}-2}}$ or

Spooled $=$ RMSE (Grissom \& Kim, 2005).

In its simplest form, a meta-analysis can be carried out as a fixedeffects model. Under the general fixed-effects model, it is assumed that there is one true effect that underlies all the studies in the analysis, consequently all differences in observed effects could be attributed to within-study variability (sampling error). In a random-effects model, however, the true effect is presumed to vary from study to study, and included between-study variability (true heterogeneity) as well as sampling error (Borenstein et al., 2009). The presence of true heterogeneity between studies was identified by the $\mathrm{Q}$ test. With heterogeneous data, a random-effects (RE) model was opted for to estimate effect size by considering the primary study a random factor (DerSimonian \& Laird, 1986). For quantification of the heterogeneity, $\mathrm{I}^{2}$ index was used (Higgins \& Thompson, 2002), which describes the proportion of total variation across the studies that is due to heterogeneity. $\mathrm{I}^{2}$-values greater than $50 \%$ were assumed to indicate substantial heterogeneity and meta-regression was carried out as an attempt to explore the source of the heterogeneity. Meta-regression extended the random-effects meta-analysis by including one or more covariates to explain heterogeneity in treatment effects. The individual covariates considered were: kind of pasture, maturity of the animals and length of the pasture access. They were tested for significance at a cut-off $\mathrm{P}$-value $\mathrm{P}<0.10$. The maturity of the animals and the duration of the pasture period were treated as continuous variables, whereas the other was dichotomous. The individual estimated effect sizes within studies were visualized by forest plots, which were constructed for each outcome variable. A positive value of the effect size indicates that indoors rearing presents higher value of the examined variables, while a negative value indicates that pastured lambs are superior to the stall-fed ones. The meta-analysis was conducted using R-software (version 2.14.2, R Development Core Team).

\section{Results and discussion}

Table 2 presents a summary of all meta-analysis findings for each indicator. As a whole, access to pasture tended to decrease the content of total lipids in lamb meat, increasing the saturated fatty acids $(\mathrm{P}<0.05)$ and $\mathrm{n}-3$ polyunsaturated fatty acids. On the other hand, the total monounsaturated fatty acids and $n-6$ were decreased $(P<0.05)$, while no effect was observed on the total PUFA. Grazing on pasture substantially decreased $(P<0.01)$ the ratio $n-6 / n-3$ in lamb meat.

\subsection{Effect of access to pasture on the total lipid content}

The impact of the pasture on the total intramuscular fat content is presented in Fig. 1. According to the random-effects model, the access to pasture had no significant effect on the content of the intramuscular lipids, however the grazing lambs tended $(P=0.11)$ to have lower intramuscular lipid content when compared to the indoors fed lambs (with five studies of a total of fourteen, reporting the opposite result for the total lipid content). The heterogeneity between studies was high (99.47\% in Table 2), and two of the tested covariates influenced the overall effect of pasture. Pasture kind contributed to the overall heterogeneity. The difference in the lipid content was most pronounced in the lambs that had access to pasture alone, than in those that received milk or concentrate, as the former displayed lower intramuscular fat content $(\mathrm{P}<0.05)$ than the lambs reared indoors (Table 3$)$. The lower lipid content in pasture reared animals could be due to the decreased stimulation of fat deposition as the opposite could be observed in the stall-fed animals following higher absorption of glucose, lactate and propionate, as stated by Majdoub, Vermorei, and Ortigues-Marty (2001). On the other hand, according to Vermorel (1988) and Hocquette, Vermorel, and Bouix (1992), the pastured lambs might experience higher energy expenditures for locomotion or thermoregulation which contributes to the lower deposition of fat. Occasionally, higher total lipid content in the muscles of pastured lambs is reported in the literature. Four of the studies in the meta-analysis reported higher content of the total fat in the meat of pasture fed lambs (Fig. 1). Nuernberg et al. (2005) found almost two times higher lipid content in the pastured lambs. The authors suggest that might be due to the adaptation period after weaning and shifting between diets, when animals had lower energy intake. The model indicated no influence of the maturity levels on the effect of pasture. However, when interacting with pasture (Popova, Gonzalez-Barron, \& Cadavez, 2015), the increasing maturity might favour the lipogenesis in muscles of the lambs on pasture. Ponnampalam et al. (2008) reported that total fat depots in sheep increased relative to lean tissue as protein accretion declined. The intramuscular fat content will inevitably increase later in the life of the animals. According to McPhee, Hopkins, and Pethick (2008), this can be interpreted to mean that the intramuscular fat depot is late maturing, however it does not mean that the rate of lipid accretion in intramuscular adipocytes is also late maturing relative to other fat depots. Usually, lambs reared on pasture do not grow as fast as the ones raised indoors, on concentrate diet, which will also contribute to the lower lipid deposition when compared to the indoor grazed animals.

Table 2

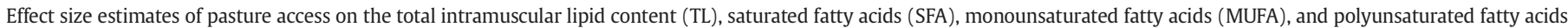
(PUFA) and n-6/n-3 ratio in lamb meat.

\begin{tabular}{|c|c|c|c|c|c|c|}
\hline Outcome & $\begin{array}{l}\text { Effect size } \\
(95 \% \mathrm{CI})\end{array}$ & SE & df & P-value of the effect & $\begin{array}{l}\text { Q-test } \\
\text { (P-value) }\end{array}$ & $\mathrm{I}^{2}$ \\
\hline TL (IMF), \% & $\begin{array}{l}0.48 \\
(-0.12-1.08)\end{array}$ & 0.30 & 13 & 0.11 & $\begin{array}{l}472.36 \\
(<0.01)\end{array}$ & 99.47 \\
\hline SFA, \% & $\begin{array}{l}-1.65 \\
(-3.18-0.12)\end{array}$ & 0.78 & 15 & 0.04 & $\begin{array}{l}601.17 \\
(<0.01)\end{array}$ & 98.02 \\
\hline MUFA, \% & $\begin{array}{l}2.29 \\
(0.35-4.23)\end{array}$ & 0.99 & 14 & 0.02 & $\begin{array}{r}1917.38 \\
(<0.01)\end{array}$ & 98.68 \\
\hline PUFA, \% & $\begin{array}{l}-0.52 \\
(-1.77-0.73)\end{array}$ & 0.64 & 14 & 0.42 & $\begin{array}{l}317.24 \\
(<0.01)\end{array}$ & 97.56 \\
\hline n-3 PUFA & $\begin{array}{l}-2.10 \\
(-3.44-0.76)\end{array}$ & 0.68 & 8 & $<0.01$ & $\begin{array}{l}783.39 \\
(<0.01)\end{array}$ & 99.80 \\
\hline n-6 PUFA & $\begin{array}{l}1.27 \\
(0.01-2.52)\end{array}$ & 0.64 & 7 & 0.05 & $\begin{array}{r}82.62 \\
(<0.01)\end{array}$ & 91.48 \\
\hline$n-6 / n-3$ & $\begin{array}{l}3.68 \\
(1.10-6.10)\end{array}$ & 1.38 & 9 & $<0.01$ & $\begin{array}{l}452.91 \\
(<0.01)\end{array}$ & 99.66 \\
\hline
\end{tabular}


Mean difference $[95 \% \mathrm{Cl}]$

\begin{tabular}{|c|c|c|}
\hline Nuernberg et al., 2005 & - & $-1.00[-1.54,-0.46]$ \\
\hline Kaczor et al., 2010 & $\mathbf{\square}$ & $-0.31[-0.48,-0.14]$ \\
\hline Santé-Lhoutellier et al., 2008 & $\mid$ & $-0.11[-0.94,0.72]$ \\
\hline Popova, Marinova, 2013 & 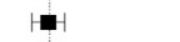 & $-0.07[-0.96,0.82]$ \\
\hline Joy et al., 2008 & $\mathbf{\square}$ & $0.01[-0.04,0.06]$ \\
\hline Panea et al., 2011 & - & $0.23[0.17,0.29]$ \\
\hline Díaz et al.,2002 & $\bar{\square}$ & $0.26[-0.15,0.67]$ \\
\hline Aurousseau et al., 2007 & $\longmapsto \cdot 1$ & $0.30[-1.86,2.46]$ \\
\hline Nürnberg et al., 2001 & + & $0.40[-0.33,1.13]$ \\
\hline Velasco et al., 2001 & $\mathbf{a}$ & $0.53[0.12,0.94]$ \\
\hline Scerra et al. 2011 & a & $0.64[0.47,0.81]$ \\
\hline Luciano et al., 2012 & $\mathbf{\square}$ & $0.78[0.62,0.94]$ \\
\hline Popova, 2007 & $\mathbf{\square}$ & $0.98[0.83,1.13]$ \\
\hline Rowe et al., 1999 & $\mathbf{n}$ & $3.94[3.40,4.48]$ \\
\hline $\begin{array}{l}\text { Effect size (with outlier) } \\
\text { Effect size (without outlier) }\end{array}$ & $\hat{\imath}$ & $\begin{array}{l}0.48[-0.12,1.08] \\
0.23[-0.07,0.54]\end{array}$ \\
\hline & 5.00 & \\
\hline
\end{tabular}

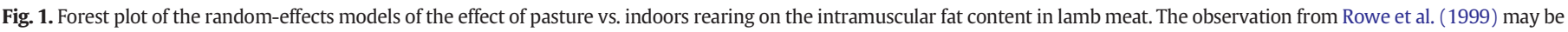
considered an outlier.

\subsection{Effect of the access to pasture on the content of the saturated fatty acids}

The total amount of saturated fatty acids in the lamb meat was influenced by the rearing system $(\mathrm{P}<0.05$ in Table 2$)$. Although few studies ( 4 of a total of 16 assessing the trait) observed lower content of saturated fatty acids in grazing lambs (Fig. 2.), the overall effect pointed that animals on pasture had higher degree of saturation in the intramuscular lipids ( $\mathrm{P}<0.05$ ). According to the meta-regression model (Table 3 ), the observed outcome was mostly due to maturity stage of animals $(\mathrm{P}<0.05)$ than to pasture itself, although grazing on pasture alone considerably augmented the difference in levels of saturated fatty acids $(P=0.15)$ between the two treatments. The increase of the saturated fatty acids in the pastured lambs indicated higher biohydrogenation in these animals and this has also been confirmed by other studies (Demirel, Ozpinar, Nazli, \& Keser, 2006). This might be due to the lower carbohydrate concentration compared to the concentrate diets, where the high carbohydrate content reduces the time of residence of the food in the rumen, thus decreasing the biohydrogenation of the

Table 3

Significant covariates influencing the effect of the pasture access on the total intramuscular lipid content (TL), saturated fatty acids (SFA), monounsaturated fatty acids (MUFA), and polyunsaturated fatty acids (PUFA), and n-6/n-3 ratio in lamb meat.

\begin{tabular}{lll}
\hline Covariate & $\begin{array}{l}\text { Coefficient } \\
(\mathrm{CI}, 95 \%)\end{array}$ & P-value \\
\hline $\mathrm{TL} \quad$ & & 0.03 \\
$\begin{array}{l}\text { 1. Pasture alone (compared to pasture }+ \\
\text { milk and pasture + concentrate) }\end{array}$ & \\
SFA & & \\
1. Maturity & $-0.05(-0.14-2.15)$ & 0.02 \\
2. Length of pasture access & $-0.01(-0.03-0.00)$ & 0.09 \\
MUFA & $4.05(0.70-7.39)$ & 0.02 \\
1. Pasture alone & $0.06(0.00-0.11)$ & 0.05 \\
2. Maturity & $0.03(0.01-0.05)$ & 0.02 \\
3. Length of pasture access & & \\
PUFA & & 0.01 \\
n-3 PUFA & $-2.82(-4.78-0.85)$ & 0.03 \\
1. Pasture alone & $-0.04(-0.08-0.01)$ & 0.03 \\
2. Maturity & $-0.02(-0.03--0.01)$ & 0.002 \\
3. Length of pasture access & & \\
n-6 PUFA & $0.03(0.00-0.06)$ & 0.07 \\
1. Maturity & & \\
n-6/n-3 & $6.08(1.22-10.93)$ & 0.02 \\
1. Pasture alone & $0.10(0.03-0.17)$ & 0.01 \\
2. Maturity & $0.04(0.01-0.07)$ & 0.03 \\
3. Length of pasture access & & \\
\hline
\end{tabular}

fatty acids (Petrova, Banskalieva, \& Dimov, 1994). The higher maturity levels of the animals favoured the saturation of the lipids in the pastured lambs $(\mathrm{P}<0.05)$, and corresponded to the longer duration of the pasture periods (Table 3 ). For most of the studies in the meta-analysis, the increased content of saturated fatty acids was due to the augmented levels of C14:0, C16:0 as well as C18:0 and only one reported higher levels of C12:0. In general, saturated fatty acids have potent and dose-response effect on the total cholesterol as well as on LDL. The individual fatty acids have been reported to have different effects with C12:0-16:0 being hypercholesterolemic while C18:0 having neutral effect. In this regard, it is necessary to further study the regulatory factors that might oppose the increase of these hypercholesterolemic fatty acids.

\subsection{Effect of the pasture access on the content of the monounsaturated fatty} acids

The content of the monounsaturated fatty acid showed the opposite trend to that of the saturated in response to the rearing system, showing significantly lower level in the lambs raised on pasture $(\mathrm{P}<0.05$ in Table 2. Furthermore, the lambs grazing pasture alone displayed significantly lower total amount of the monounsaturated fatty acids than the lambs receiving supplements $(\mathrm{P}<0.05$ in Table 3$)$. The regression coefficient in these lambs was the highest -4.05 vs. 2.29 and 0.63 respectively in the lambs receiving pasture + milk and the ones that additionally received concentrate. This pattern corresponds to the decrease in the total lipid content due to the pasture systems, as in general the higher lipid content is associated with accumulation of MUFA rather than SFA. The rest of the tested covariates - maturity and duration of the experiment - affected significantly the overall effect $(\mathrm{P}<0.05)$. The meta-regression for the maturity stage and duration of the trial revealed positive relationship between these two covariates and the effect size with higher maturity and duration favouring the desaturation of the fatty acids in the meat of the indoors reared lambs (i.e., hence decreasing in the animals reared on pasture). Usually these two covariates are associated with the increase in the age of the animals as well as their slaughter weight, and several studies report increase in the desaturation of the lipids in the adipose depots with ageing of the ruminants and higher slaughter weight (Hocquette, Graulet, \& Olivecrona, 1998). Only three of the studies used in this meta-analysis reported higher monounsaturated fatty acids in the pastured lambs (Fig. 3). Scerra et al. (2011) showed significantly augmented total MUFA in the lambs reared on pasture that corresponded to the reduced SFA in the same trial. 
Mean difference $[95 \% \mathrm{Cl}]$

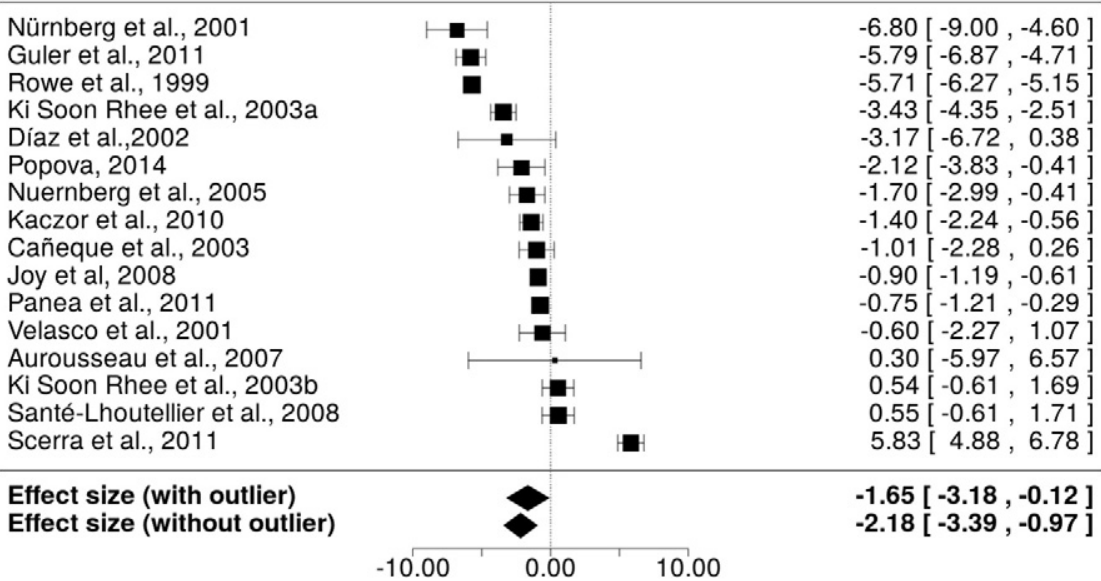

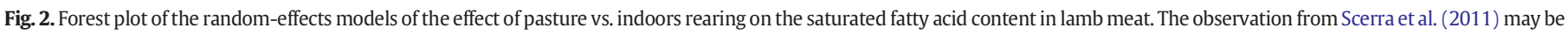
considered an outlier.

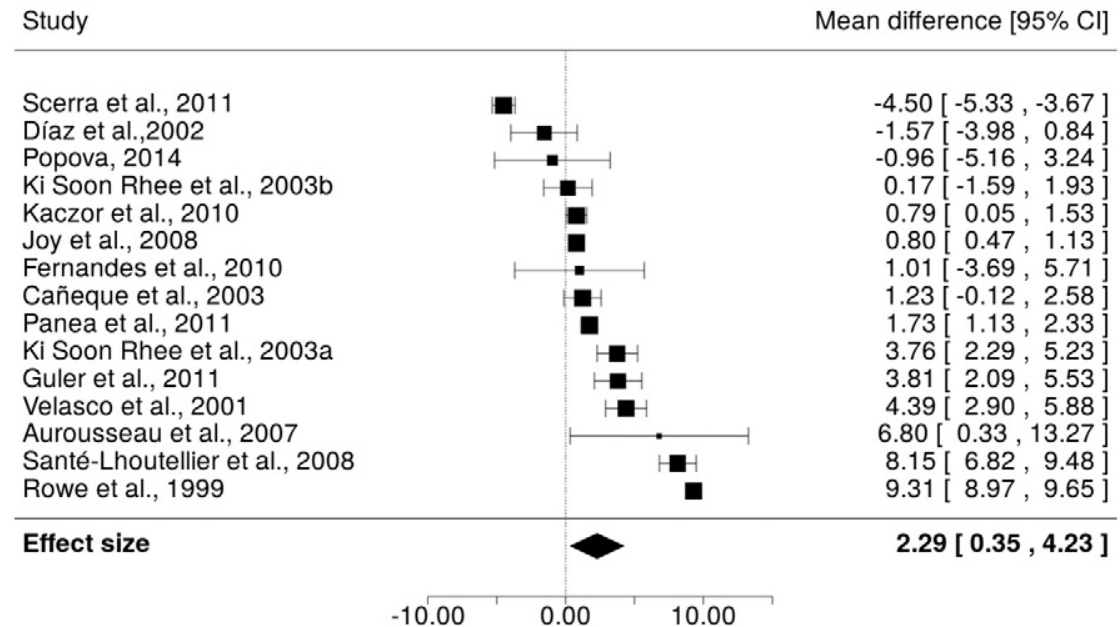

Fig. 3. Forest plot of the random-effects model of the effect of pasture vs. indoors rearing on the monounsaturated fatty acid content in lamb meat.

Most of the studies included in the meta-analysis reported higher content of MUFA in the indoors reared lambs, due mainly to augmented levels of C18:1, while the results for the C16:1 were not consistent. According to Jenkins, Thies, and Fotouhi (1994), feeding high grain diet significantly increases the absorption of C18:1 since it is abundant in the grain cereals. According to Bauman, Baumgard, Corl, and Griinari (2000), the content of the oleic acid increases with lipid deposition due to the increased activity of delta 9-desaturases. The increased content of oleic acid suggest positive effect of the indoors rearing based on concentrates for the fatty acid profile of lamb meat. This fatty acid

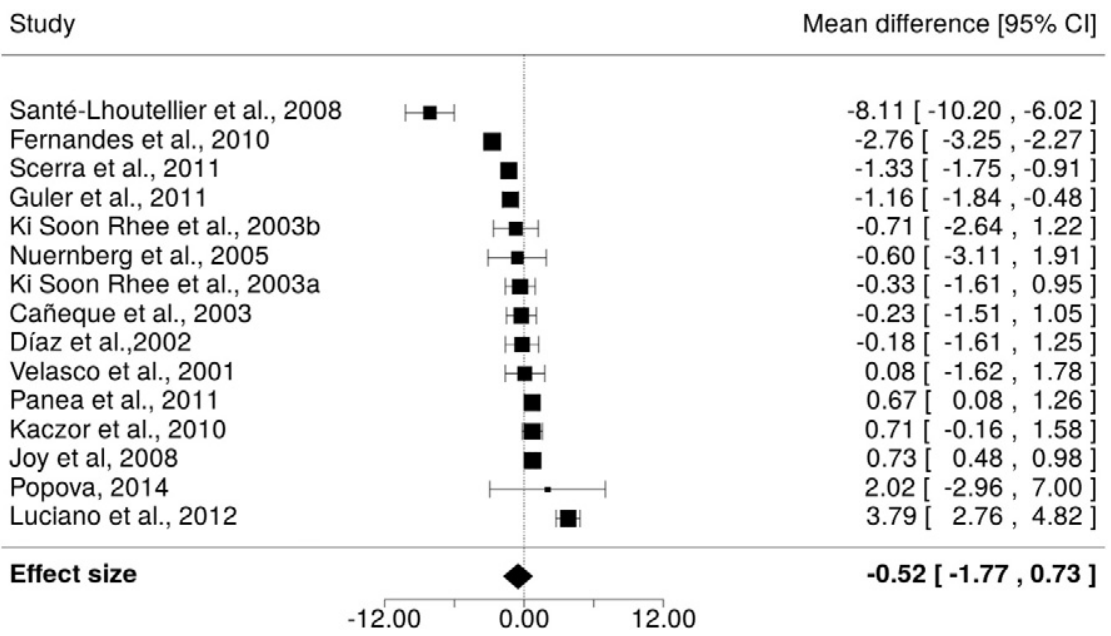

Fig. 4. Forest plot of the random-effects model of the effect of pasture vs. indoors rearing on the polyunsaturated fatty acid content in lamb meat. 
Mean difference $[95 \% \mathrm{Cl}]$

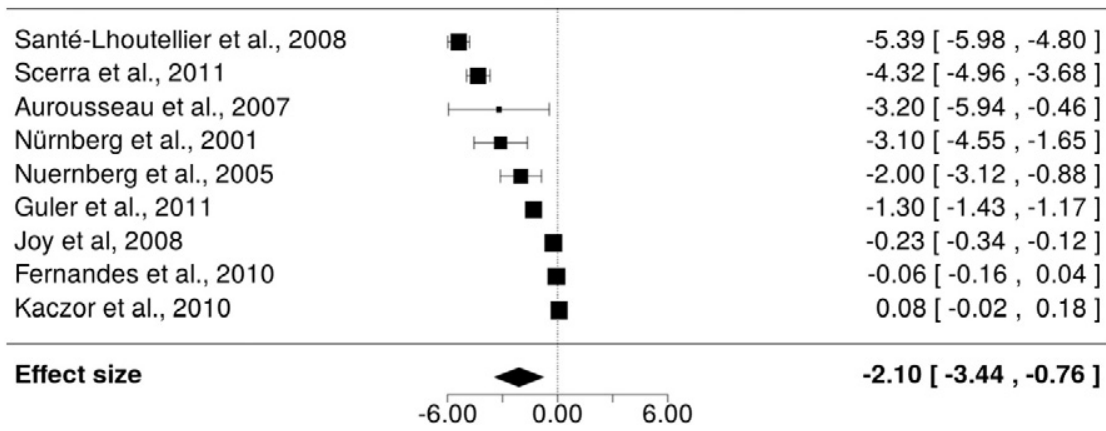

Fig. 5. Forest plot of the random-effects model of the effect of pasture vs. indoors rearing on the n-3 polyunsaturated fatty acid content in lamb meat.

is more stable in comparison to the polyunsaturated fatty acids. It is considered also that oleic acid might reduce the levels of blood cholesterol.

\subsection{Effect of the pasture access on the content of the polyunsaturated fatty acids}

As a whole, the random-effects model did not indicate any significant difference between treatments in the total amount of the polyunsaturated fatty acids in the lamb meat (Table 2; Fig. 4). However, the lambs reared on pasture alone and for a longer duration tended to have higher total PUFA that those reared indoors (Table 3). Significant effect $(\mathrm{P}<0.01)$ of the pasture rearing was determined in regard to the content of the n-3 polyunsaturated fatty acids (Fig. 5). Their content was higher than in the indoors reared animals as significant part of this augmentation was due to pasture alone $(\mathrm{P}<0.01)$ and the longer duration of the pasture access in the studies $(\mathrm{P}<0.01)$. The higher maturity stage also pointed towards higher deposition of n-3 PUFA in the pastured lambs $(\mathrm{P}<0.05$ in Table 3$)$. The increase in the content of the $\mathrm{n}-$ 3 polyunsaturated fatty acids is mainly due to the accumulation of C18:3. This fatty acid is abundant in grass (Bas \& Morand-Fehr, 2000) and is a precursor for the synthesis of the rest of the n-3 long chain PUFA. The higher content of linolenic acid coming from the grass shows that, despite the intensive biohydrogenation in the pastured lambs, a significant part of this fatty acid escapes saturation and undergoes further elongation to long chain PUFA. According to Ben Salem, Krzeminski, Ferlay, and Doreau (1993), C18:3 might be protected additionally in the rumen if the feed is not crushed or ground.

On the other hand, the content of the n-6 PUFA decreased $(\mathrm{P}<0.05$; Table 2, Fig. 6 ) in the pastured lambs, as those on pure pasture tended to have lower content of n-6 PUFA. The decreased content of n-6 PUFA is explained with the lower amount of C18:2 accumulated in the intramuscular lipids of pastured lambs since this fatty acid is in high amounts

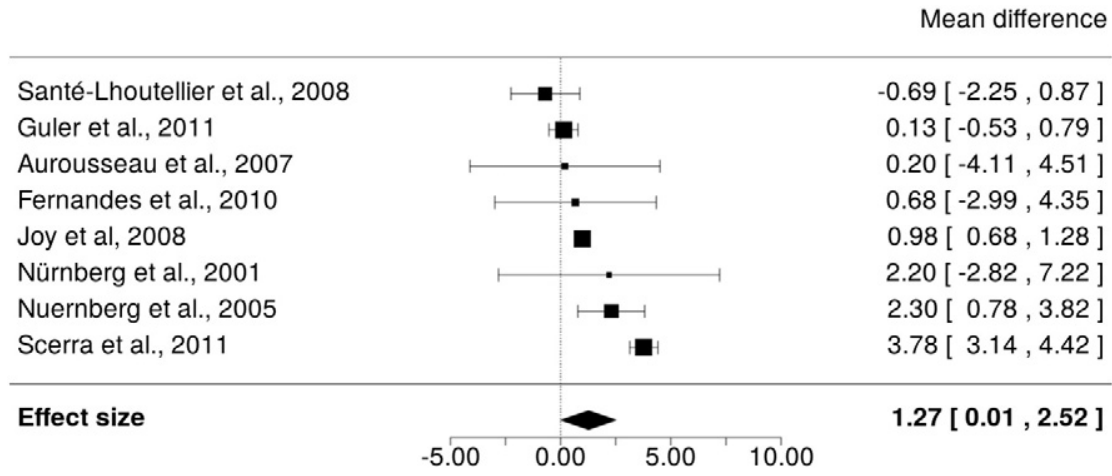

Fig. 6. Forest plot of the random-effects model of the effect of pasture vs. indoors rearing on the n- 6 polyunsaturated fatty acid content in lamb meat.

Study

\begin{tabular}{|c|c|c|}
\hline Kaczor et al., 2010 & घ & $0.07[-0.30,0.44]$ \\
\hline Velasco et al., 2001 & a & $0.62[0.40,0.84]$ \\
\hline Joy et al, 2008 & - & $1.04[0.50,1.58]$ \\
\hline Aurousseau et al., 2007 & 口 & $1.10[0.51,1.69]$ \\
\hline Nuernberg et al., 2005 & a & $1.10[0.85,1.35]$ \\
\hline Díaz et al.,2002 & a & $1.37[0.94,1.80]$ \\
\hline Nürnberg et al., 2001 & . $\quad \longrightarrow$ & $4.90[0.16,9.64]$ \\
\hline Panea et al., 2011 & - & $6.83[6.14,7.52]$ \\
\hline Scerra et al., 2011 & $\mapsto \mathbf{\square}$ & $9.67[8.09,11.25$ ] \\
\hline Guler et al., 2011 & $\longmapsto$ & $11.90[7.55,16.25]$ \\
\hline & & $3.60[1.10,6.10]$ \\
\hline
\end{tabular}

Fig. 7. Forest plot of the random-effects model of the effect of pasture vs. indoors rearing on the n-6/n-3 ratio in lamb meat. 
in the concentrates and not in the grass. The maturity seemed to contribute substantially to the difference between treatments $(\mathrm{P}=0.07$ in Table 3), as higher maturity increased the effect size favouring the increase of $n-6$ PUFA in the indoors reared animals. This might be explained to the higher incorporation of 18:2 n- 6 in the polar but also neutral lipid fraction in the muscles in more mature animals. The capacity for incorporation of polyunsaturated fatty acids in the phospholipids is limited and linoleic fatty acid competes more effectively that C18:3. However, extra incorporation of these two fatty acids may occur in triacylglycerols with maturing of the animals but also greater for C18:2n-6 (Wood et al., 2008).

The ratio n- $6 / n-3$ was considerably influenced by the rearing system, as it was significantly lower $(P<0.01)$ in the grazing lambs (Table 2) as the ones on pasture alone displayed lower values of the ratio when compared to the lambs that had also access to milk or concentrate $(\mathrm{P}<0.05$; Table 3$)$. Furthermore, the lambs of higher maturity and fed longer on pasture revealed significantly lower values $(\mathrm{P}<0.05)$ of $n-6 / n-3$ ratio, corresponding to the influence of these covariates on the content of the $n-3$ PUFA in the pastured lambs. The values of the ratio $n-6 / n-3$ are regarded as an indicator for the dietetic quality of meat. The recommended values are below 4 . With exception of Kaczor et al. (2010) and Joy et al. (2008) reporting values of $n-6 / n-37.81$ and 5.04 , respectively; in all the studies in the meta-analysis, the meat of the lambs reared on pasture were below 4 (1.2-3.16) (Fig. 7).

\section{Conclusions}

Meta-analysis was a useful tool to assess and summarize the knowledge about the influence of the pasture rearing on the lipid content and composition of lamb meat. High variability between studies in the meta-analysis existed but it was possible to partially explain it by including covariates such as pasture conditions, maturity of the animals and length of trial period that helped us to find significant effects pointing to the advantages of the pasture rearing over the concentrate-based diets in ruminants. The results of the study showed that, although increasing the saturated fatty acids and decreasing the monounsaturated, rearing on pasture led to lower fat content in lamb meat. In addition, grazing considerably increased the content of n-3 PUFA and decreased the ratio $n-6 / n-3$ in lamb meat, thus indicating that pasture rearing can be recommended as a successful strategy towards improvement of meat dietetic quality.

\section{Acknowledgments}

Dr. Teodora Popova wishes to acknowledge the financial support provided by the Erasmus + Programme, Key Action 1: Learning mobility for individuals, administered by the European Union (№ 2014-1BG01-KA103-000110).

Dr. Gonzales-Barron wishes to acknowledge the financial support provided by the Portuguese Foundation for Science and Technology (FCT) through the award of five-year Investigator Fellowship (IF) in the mode of Development Grants (IF/00570).

\section{References}

Aurousseau, B., Bauchart, D., Faure, X., Galot, A. L., Prache, S., \& Micol, D. (2007). Indoor fattening of lambs raised on pasture: Influence of stall finishing duration on lipid classes and fatty acids in the longissimus thoracis muscle. Meat Science, 76, 241-252.

Baguley, T. (2009). Standardized or simple effect size: What should be reported? British Journal of Psychology, 100, 603-617.

Bas, P., \& Morand-Fehr, P. (2000). Effect of nutritional factors on fatty acid composition of lamb fat deposits. Livestock Production Science, 64, 61-79.

Bauman, D. E., Baumgard, L. H., Corl, B. A., \& Griinari, J. M. (2000). Biosynthesis of conjugated linoleic acid in ruminants. Proceedings American Society of Animal Science, 1999 (http://www.asas.org/symposia/proceedings/0937.pdf).

Ben Salem, H., Krzeminski, R., Ferlay, A., \& Doreau, M. (1993). Effect of lipid supply in in vivo digestion in cows: Comparison of hay and corn silages diets. Canadian Journal of Animal Science, 73, 547-557.
Borenstein, M., Hedges, L. V., Higgins, J. P. T., \& Rothstein, H. R. (2009). Introduction to meta-analysis. Chichester, UK: John Wiley \& Sons, Ltd.

Cañeque, V., Velasco, S., Díaz, M. T., Huidobro, F. R., Pérez, C., \& Lauzurica, S. (2003). Use of whole barley with a protein supplement to fatten lambs under different management systems and its effect on meat and carcass quality. Animal Research, 52, 271-285.

Carriquiry, M., Weber, W. J., \& Crooker, B. A. (2008). Administration of bovine somatotropin in early lactation: A meta-analysis of production responses by multiparous Holstein cows. Journal of Dairy Science, 91, 2641-2652.

Cividini, A., Levart, A., \& Zgur, S. (2008). Fatty acid composition as affected by production system, weaning and sex. Acta Agriculturae Slovenica, Supplement, 2, 47-52.

Cividini, A., Levart, A., Žgur, S., \& Kompan, D. (2014). Fatty acid composition of lamb meat from the autochthonous Jezersko-Solčava breed reared in different production systems. Meat Science, 97, 480-485.

DeCoster, J. (2004). Meta-analysis notes. Accessed March 2008. http://www.stat-help. com/notes.html.

Demirel, G., Ozpinar, H., Nazli, B., \& Keser, O. (2006). Fatty acids of lamb meat from two breeds fed different forage: Concentrate ratio. Meat Science, 72, 229-235.

DerSimonian, R., \& Laird, N. (1986). Meta-analysis in clinical trials. Controlled Clinical Trials, 7, 177-188.

Diaz, M. T., Velasco, S., Caneque, V., Lauzurica, S., Ruiz de Huidobro, F., \& Pérez, C. (2002) Use of concentrate or pasture for fattening lambs and its effect on carcass and meat quality. Small Ruminant Research, 43, 257-268.

Fernandes, M. A. M., Monteiro, A. L. G., Espírito, C. H., Poli, C., Simionato de Barros, C., \& de Almeida, R. (2010). Composição tecidual da carcaça e perfil de ácidos graxos da carne de cordeiros terminados a pasto ou em confinamento. Revista Brasileira de Zootecnia, 39, 1600-1609.

Fernandez-Duque, E. (1997). Comparing and combining data across studies: Alternatives to significance testing. Oikos, 79, 616-618.

Fritz, C. O., Morris, P. E., \& Richler, J. J. (2012). Effect size estimates: Current use, calculations and interpretation. Journal of Experimental Psychology: General, 141, 2-18.

Gatellier, P., Mercier, Y., \& Renerre, M. (2004). Effect of diet finishing mode (pasture or mixed diet) on antioxidant status of Charolais bovine meat. Meat Science, 67, 385-394.

Grissom, R. J., \& Kim, J. J. (2005). Effect sizes for research: A broad practical approach. New York, NY: Psychology Press.

Guler, G. O., Aktumsek, A., \& Karabacak, A. (2011). Effect of feeding regime on fatty acid composition of Longissimus dorsi muscle and subcutaneous adipose tissue of Akkaraman lambs. Kafkas Üniversitesi Veteriner Fakültesi Dergisi, 17, 885-892.

Higgins, J. P. T., \& Thompson, S. G. (2002). Quantifying heterogeneity in meta-analysis Statistics in Medicine, 21, 1539-1558.

Hocquette, J. F., Graulet, B., \& Olivecrona, T. (1998). Lipoprotein lipase activity and mRNA levels in bovine tissues. Comparative biochemistry and physiology part BBiochemistry and Molecular Biology121, 201-212.

Hocquette, J. F., Vermorel, M., \& Bouix, J. (1992). Influence du froid, du vent et de la pluie sur les depenses energetiques et la thermoregulation de sept types genetiques de brebis. Genetique, Selection, Evolution, 24, 147-169.

Jenkins, T. C., Thies, E. J., \& Fotouhi, N. (1994). Dietary soybean oil changes lypolitic rate and composition of fatty acids in plasma membranes of ovine adipocytes. British Journal of Nutrition, 124, 566-570.

Joy, M., Ripoll, G., \& Delfa, R. (2008). Effects of feeding system on carcass and non-carcass composition of Churra Tensina light lambs. Small Ruminant Research, 78, 123-133.

Kaczor, U., Borys, B., \& Pustkowiak, H. (2010). Effect of intensive fattening of lambs with forages on the fatty acid profile of intramuscular and subcutaneous fat. Czech Journal of Animal Science, 55, 408-419.

Rhee, K. S., Lupton, C. J., Ziprin, Y. A., \& Rhee, K. C. (2003a). Carcass traits of Rambouillet and Merino $\times$ Rambouillet lambs and fatty acid profiles of muscle and subcutaneous adipose tissues as affected by new sheep production system. Meat Science, 65, 693-699.

Rhee, K. S., Lupton, C. J., Ziprin, Y. A., \& Rhee, K. C. (2003b). Effects of sheep production systems on oxidative storage stability of lean lamb patties. Meat Science, 65, 701-770.

Luciano, G., Biondi, L., Pagano, R. I., Scerra, M., Vasta, V., \& López-Andrés, P. (2012). The restriction of grazing duration does not compromise lamb meat colour and oxidative stability. Meat Science, 92, 30-35.

Majdoub, L., Vermorei, M., \& Ortigues-Marty, I. (2001). Net nutrient metabolism in hindlimb of growing lambs supplemented with propionate: Animal and human growth and development. Regulatory mechanisms; session: regulation of muscle growth and lipid metabolism. In: Proceedings of the French-Polish Symposium, Paris, France (pp. 25-26) September, C24, p. 51.

McPhee, M. J., Hopkins, D. L., \& Pethick, D. W. (2008). Intramuscular fat levels in sheep muscle during growth. Australian Journal of Experimental Agriculture, 48, 904-909.

Nuernberg, K., Nuernberg, G., Ender, K., Dannenberger, D., Schabbel, W., \& Grumbach, S. (2005). Effect of grass vs. concentrate feeding on the fatty acid profile of different fat depots in lambs. European Journal of Lipid Science and Technology, 107, 737-745.

Nürnberg, K., Grumbach, S., Nürnberg, G., Härtung, M., Zupp, W., \& Ender, K. (2001). Influence of breed and production system on meat quality and fatty acid composition in lamb muscle. Archiv Tierzuch, Dummerstorf, 44(Special Issue), 351-360.

Osenberg, C. W., \& St. Mary, C. M. (1998). Meta-analysis: Synthesis or statistical subjugation? Integrative Biology: Issues, News and Views, 1, 43-48.

Panea, B., Carrasco, S., Ripoll, G., \& Joy, M. (2011). Diversification of feeding systems for light lambs: sensory characteristics and chemical composition of meat. Spanish Journal of Agricultural Research, 9, 74-85.

Petrova, Y., Banskalieva, V., \& Dimov, V. (1994). Effect of feeding on distribution of fatty acids at $\mathrm{Sn}-2$ position in triacylglycerols of different adipose tissues in lambs. Small Ruminant Research, 13, 263-267.

Ponnampalam, E. N., Butler, K. L., Hopkins, D. L., Kerr, M. G., Dunshea, F. R., \& Warner, R. D. (2008). Genotype and age effects on sheep meat production 5. Lean meat and fat 
content in the carcasses of Australian sheep genotypes at 20-, 30- and 40-kg carcass weights. Australian Journal of Experimental Agriculture, 48, 933-937.

Popova, T., Gonzalez-Barron, U., \& Cadavez, V. (2015). Meta-analysis of the effect of pasture access vs. indoors rearing on the intramuscular fat content in lamb meat. XIX Congresso de Zootechnia “Diversidade Na Porduçao“, Livro de Atas (pp. 139).

Popova, T. (2007). Effect of the rearing system on the fatty acid composition and oxidative stability of the M. longissimus lumborum and M. semimembranosus in lambs. Small Ruminant Research, 71, 150-157.

Popova, T. (2014). Fatty acid composition of Longissimus dorsi and Semimembranosus muscles during storage in lambs reared indoors and on pasture. Emirates Journal of Food and Agriculture, 26, 302-308.

Popova, T., \& Marinova, P. (2013). Carcass composition and meat quality in lambs reared indoors and on pasture. Agricultural Science and Technology, 5, 325-330.

Rowe, A., Macedo, F. A. F., Visentainer, J. V., Souza, N. E., \& Matsushita, R. (1999). Muscle composition and fatty acid profile in lambs fattened in drylot or pasture. Meat Science, 51, 283-288.

Sales, J. (2009). The effect of fish meal replacement by soybean products on fish growth: A meta-analysis. British Journal of Nutrition, 102, 1709-1722.
Santé-Lhoutellier, V., Engel, E., \& Gatellier, P. (2008). Assessment of the influence of diet on lamb meat oxidation. Food Chemistry, 109, 573-579.

Scerra, M., Luciano, G., Caparra, P., Foti, F., Cilione, C., \& Giorgi, A. (2011). Influence of stall finishing duration of Italian Merino lambs, raised on pasture on intramuscular fatty acid composition. Meat Science, 89, 238-242.

Velasco, S., Cañeque, V., Pérez, C., Lauzurica, S., Díaz, M. T., \& Huidobro, F. (2001). Fatty acid composition of adipose depots of suckling lambs raised under different production systems. Meat Science, 59, 325-333.

Vermorel, M. (1988). Nutrition energetique (Energy Nutrition). In R. Jarrige (Ed.), Alimentation des bovins, ovins and caprins. (pp. 57-74)Paris: INRA.

Wilkinson, L., \& Task Force on Statistical Inference (1999). Statistical methods in psychology journals: Guidelines and explanations. American Psychologist, 54, 594-604.

Wood, J. D., Enser, M., Fisher, A. V., Nute, G. R., Sheard, P. R., \& Richardson, R. I. (2008). Fat deposition, fatty acid composition and meat quality: A review. Meat Science, 78, 343-358. 